\title{
Rheumatoid neuropathy: a histological and electrophysiological study
}

\author{
R. O. WELlER, F. E. BRUCKNER, AND M. ANNE CHAMBERLAIN \\ From the Department of Pathology, Guy's Hospital Medical School, London, and Department of Rheumatology \\ and Physical Medicine, Middlesex Hospital, London
}

SUMMARY Peripheral nerves in five patients with rheumatoid neuropathy were examined electro- $\frac{\widehat{D}}{\Omega}$ physiologically and by sural nerve biopsy. There was close correlation between the clinical severityos of the disease and the degree of nerve damage found histologically and by EMG. Group 1 patients $\overrightarrow{-}$ with a mild distal sensory neuropathy showed varying degrees of axonal degeneration in the largemyelinated fibres and some segmental demyelination. Group 2 patients with a severe, rapidlyc. progressive sensori-motor neuropathy had extensive loss of myelinated fibres. In one case all the large fibres had degenerated. The second case had lost both large and small myelinated fibres together with many of the non-myelinated axons. The major nerve damage in both groups appearedic to be axonal degeneration but some segmental demyelination was detected. Occlusive vasculariv disease in the vasa nervorum was considered to be the major cause of the nerve damage.

Chamberlain and Bruckner (1970) have presented the clinical findings in a series of patients with peripheral neuropathies associated with rheumatoid arthritis. They excluded the compression neuropathies and divided the rest into two main groups. Group 1 consists of patients where sensory symptoms predominate and are mild in character. Group 2 comprises those with severe motor and sensory signs often associated with malignant rheumatoid disease and signs of vasculitis.

The purpose of this investigation is to study the type and extent of peripheral nerve damage that occurs in rheumatoid neuropathy. Sural nerve biopsies were taken from three patients in group 1 and from two patients in group 2, and examined by light and electron microscopy. In addition to the nerve fibres, we were able to study the blood vessels supplying the nerves; this is particularly important as previous workers have found evidence of vasculitis in the vasa nervorum in rheumatoid neuropathy (Cruickshank, 1954; Hart and Golding, 1960; Pallis and Scott, 1965).

The rather limited view gained by examining only small pieces of sural nerve was extended by electrophysiological studies of other peripheral nerves. In this way a composite picture can be assembled for each patient and the major type of nerve damage in each group of patients characterized.
CLINICAL MATERIAL AND CASE HISTORIES

GROUP 1 A patchy gloveand stocking hypoaesthesia and hypoalgesia is characteristic of this group; itộंs $\vec{b}$ approximately symmetrical, affecting the feet moreoften than the hands. The onset is insidious, unobtrusive, and often associated with relativelyo benign rheumatoid arthritis. The sex ratio is that of rheumatoid disease; with nodules and periarticularo erosions frequently present. The arthritis in mose patients is seropositive, the Rose's titre being onlye moderate.

\section{CASE 1}

I.B. is a 70 -year-old housewife with a 20 -year history of rheumatoid arthritis. Her arthritis is seronegative, erosive, and anodular; there is typical multiple joint? involvement.

Mrs B. first developed paraesthesiae and hypoalgesia in the hands six years ago; the symptoms gradually? increased and now involve the lower limbs. Hypo aesthesia and hypoalgesia are present on the dorsal surface of the right hallux, left hallux, and left second toe; there are sensory changes in the fingers of both hands, but the palmar aspect of the left fourth finger and the dorsa surface of the left thumb are spared. Some sensory loss can be detected in the dorsum of the right hand. The areas involved has extended slightly during the last year despite bilateral carpal tunnel decompression in 1966. Although 
it is difficult to assess muscular power in the presence of chronic joint disease, there appeared to be no motor deficit.

No family history of neurological disorders was elicited, and apart from an ESR of $16 \mathrm{~mm}$ in the first hour, all the routine investigations were normal. She has been treated only with salicylates.

\section{CASE 2}

Miss E.T. is a 52-year-old headmistress who has had definite rheumatoid arthritis since 1953 but is only mildly incapacitated. She has no nodules, and her sheep cell agglutination titre is only weakly seropositive. Almost all joints have been involved at some time and many show erosive changes. There is narrowing of C4-5 and C5-6 disc spaces but with no changes at higher levels. At no time has the disease been complicated by nailfold lesions or other evidence of vasculitis.

Five years ago the patient noticed numbness and paraesthesiae in the hands and feet. Clinical examination revealed hypoaesthesia and hypoalgesia in both arms up to the mid-forearm and in both legs up to the knees. In addition, vibration sense was absent in the legs as high as the iliac crests. There was no weakness or muscle tenderness in the lower limbs but the ankle reflexes were absent. Minimal weakness was present in the intrinsic muscles of both hands. In addition some median nerve involvement was found on the left which improved following carpal tunnel decompression. Some extension of the area of sensory deficit has been observed during the last year.

No family history of neurological disease was found. Routine clinical investigations revealed no other cause for the neuropathy. The patient has been treated with $7.5 \mathrm{mg}$ prednisolone daily since 1957 and before that she was given a total of $600 \mathrm{mg}$ gold between 1955 and 1957 ; she also takes soluble aspirin, diazepam, and vitamin $\mathbf{K}$.

\section{CASE 3}

Ernest W. is a 75-year-old retired chef who developed rheumatoid arthritis in 1964; the disease is anodular, seropositive (latex test), and erosive, but does not markedly interfere with the patient's activities. Clinically, the arthritis involves the wrists, metacarpophalangeal, and metatarso-phalangeal joints. Radiography of the cervical spine shows moderate degenerative changes.

The patient first developed numbness of the hands and feet one year before the onset of the arthritis; since this time the symptoms have become more severe. Some 18 months before the first symptoms appeared, Mr. W. had been taking small doses of thalidomide; his neuropathy, however, was not thought to be related to this. No family history of neurological disease was revealed.

On examination there is muscular weakness in the limbs; hypoalgesia and hypoaesthesia are present in the distal half of both feet and on the dorsal surfaces of both hands up to wrist level. The palm of the right hand is spared but sensory changes are found in the left palm. Severe wasting is present in those muscles of the left hand innervated by the median nerve.
Laboratory investigations elicited no other aetiological factors in his neuropathy.

GROUP 2 In this group sensory symptoms rarely antedate the profound, distal motor weakness by more than a few weeks; often the picture is that of a mononeuritis multiplex. Males predominate and patients are unwell in a way that is vaguely different from their previous malaise; most of them deteriorate rapidly and the mortality rate is high. The stigmata of malignant rheumatoid disease such as leg ulceration, bowel ulceration and perforation, and myocardial infarction are frequently present; these are probably all due to arteritic lesions. Nailfold lesions are slightly more common than in group 1. All patients have nodules and periarticular erosions together with a positive sheep cell test that is often of high titre.

\section{CASE 4}

John T. was a 68-year-old married business man who was still working with the aid of an invalid chair despite severe classical rheumatoid arthritis. The disease began in 1942 and was accompanied by nodules, erosive changes in the joints, and sheep cell agglutination positive to a titre of $1: 256$. All joints had been involved at some stage; in addition, erosion of the odontoid process had occurred but without atlanto-axial subluxation.

Nailfold lesions were first noticed in 1965 and a month later the patient noticed paraesthesiae in the right foot; within a further four weeks he had developed weakness of eversion in this foot. There was no disturbance of autonomic function.

Clinical examination in 1966 revealed hypoalgesia and hypoaesthesia of the distal two-thirds of both legs and in the feet. There was marked weakness of eversion of the right foot and moderate weakness in the long flexors, extensors and peronei on both sides; ankle reflexes were absent.

No family history of neurological disease was obtained. Mr. T. died from coronary artery occlusion and myocardial infarction early in 1969 just over one year after biopsy.

Since 1957 he had been treated with prednisolone $15 \mathrm{mg}$ daily, but the dose had been reduced to $12.5 \mathrm{mg}$ one month before the appearance of nailfold lesions.

\section{CASE 5}

Mrs. B.M. is a 38-year-old housewife with two children who has had rapidly progressive classical rheumatoid arthritis since the age of 32 years. When seen in 1967 her arthritis was nodular, seropositive, and erosive. She was severely disabled. Almost all the joints have been involved although the cervical spine is spared. Nailfold lesions appeared only after the onset of neurological symptoms.

The patient first developed symptoms of a peripheral neuropathy in 1967 with the onset and rapid progression of both sensory and motor signs. Left foot drop was 
quickly followed by loss of dorsiflexion of the right foot. Hypoaesthesia and hypoalgesia were found on the lateral aspects of both legs to the ankles and extending on to both anterior and posterior aspects around the ankles; reflexes were absent in both ankles; no muscle tenderness was detected. Bilateral ulnar and median nerve lesions appeared a little later. At this time she developed the clinical signs of a gastric ulcer.

No family history of neurological disease has been elicited.

During the past two years she has been given azathiaprine $100 \mathrm{mg}$ daily and her neurological signs have not progressed.

Abnormal results from clinical investigations include an ESR of $55 \mathrm{~mm}$ and a sheep cell agglutination positive to a titre $1: 512$.

\section{METHODS}

HISTOLOGY AND ELECTRON MICROSCOPY OF SURAL NERVE BIOPSIES Short pieces of sural nerve were taken at the ankle under general anaesthesia and fixed by immersion for four hours in $3 \%$ glutaraldehyde buffered to $p \mathbf{H ~ 7 . 4}$ by 0.067 molar sodium cacodylate. After post fixation in $1 \%$ osmium tetroxide (Palade, 1952) the nerves were dehydrated in alcohol and embedded in Araldite.

1 to $2 \mu$ Araldite sections for light microscopy were cut on an LKB ultratome with glass knives and stained with $1 \%$ toluidine blue. Selected areas from some blocks were sectioned for electron microscopy. The thin sections were stained with uranyl acetate and lead citrate and viewed in RCA EMU 3e or 4 electron microscopes.

The mean diameters of $\mathbf{2 0 0}$ myelinated fibres were measured in each case upon light micrographs magnified 688 times.

ELECTROPHYSIOLOGICAL TECHNIQUE Motor studies of the lateral popliteal nerve were undertaken as described by Thomas, Sears, and Gilliatt (1959) and mixed nerve potentials as detailed by Gilliatt, Goodman, and Willison (1961). The medial popliteal nerve was occasionally investigated in a similar manner. Sensory action potentials from the median and ulnar nerves at the wrist were obtained by stimulation of the appropriate fingers with ring electrodes (Dawson, 1956). Motor studies of the ulnar and median nerves were performed using the technique described by Thomas et al. (1959).

Subjects were examined in a warm room; the skin temperature of the patients' legs did not fall below $29 \cdot 5^{\circ} \mathrm{C}$.

\section{HISTOLOGICAL RESULTS}

NORMAL HUMAN NERVE

The normal human sural nerve used in this study was from a 35-year-old male. It was fixed primarily in osmium and not in glutaraldehyde.

A human sural nerve consists of a varying number of fasciculi each containing myelinated and non-myelinated nerve fibres and surrounded by a perineurium. Between the fascicles is the epineurial connective tissue and this usually contains a single, large nutrient artery. Smaller blood vessels run longitudinally between the nerve fibres -that is, within the endoneurium.

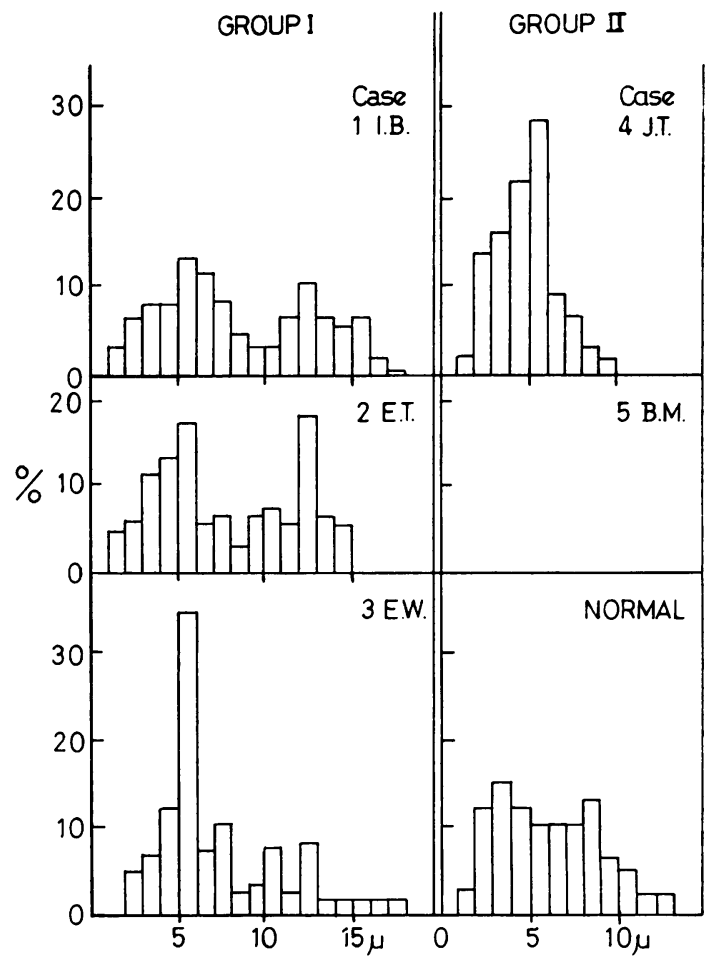

FIG. 1. Histograms to show the fibre spectrum of myeli囚 ated nerve fibres in the five patients with rheumatotid neuropathy and in normal sural nerve (abscissa: myelinater. fibre diameters in micra).

The myelinated fibres fall into two major size ranges (see Fig. 2). When a histogram is constructed the fibre diameters show a bimodal distribution (Figs. 1 and 2). The large fibres in our preparation show a peak at 8 to $9 \mu$ and the smaller fibres at 3 to $4 \mu$. These figures are in close agreement with those of Dyck, Gutrecht, Bastron, Karnes, and Dale (1968); in both instances osmium tetroxide was used as the primary fixative. There $\overrightarrow{0}$ is some variation in the exact figures which probably depends upon preparative methods. Ochoa and Mair (1969a) found major peaks in their bimodal distribution at $11 \mu$ and $5 \mu$. One of the most important features of the histograms therefore is the presence of a bimodal distribution of fibre diameters.

Although groups of non-myelinated axons and their accompanying Schwann cells can be seen with the light microscope (Fig. 2), they are more adequately studied with the electron microscope. Ultrastructurally, human non-myelinated fibres show many similarities to those in 을 other mammals (Gamble and Eames, 1964; Weller, 1967; Ochoa and Mair, 1969a); but they are somewhat larger, reaching $3 \mu$ in axon diameter but with a peak at $1.4 \mu$ (Ochoa and Mair, 1969a).

HISTOLOGICAL ASSESSMENT OF NERVE DAMAGE Myelinated $\mathbb{N}$ nerve fibre damage in peripheral nerves is assessed by $N$ 

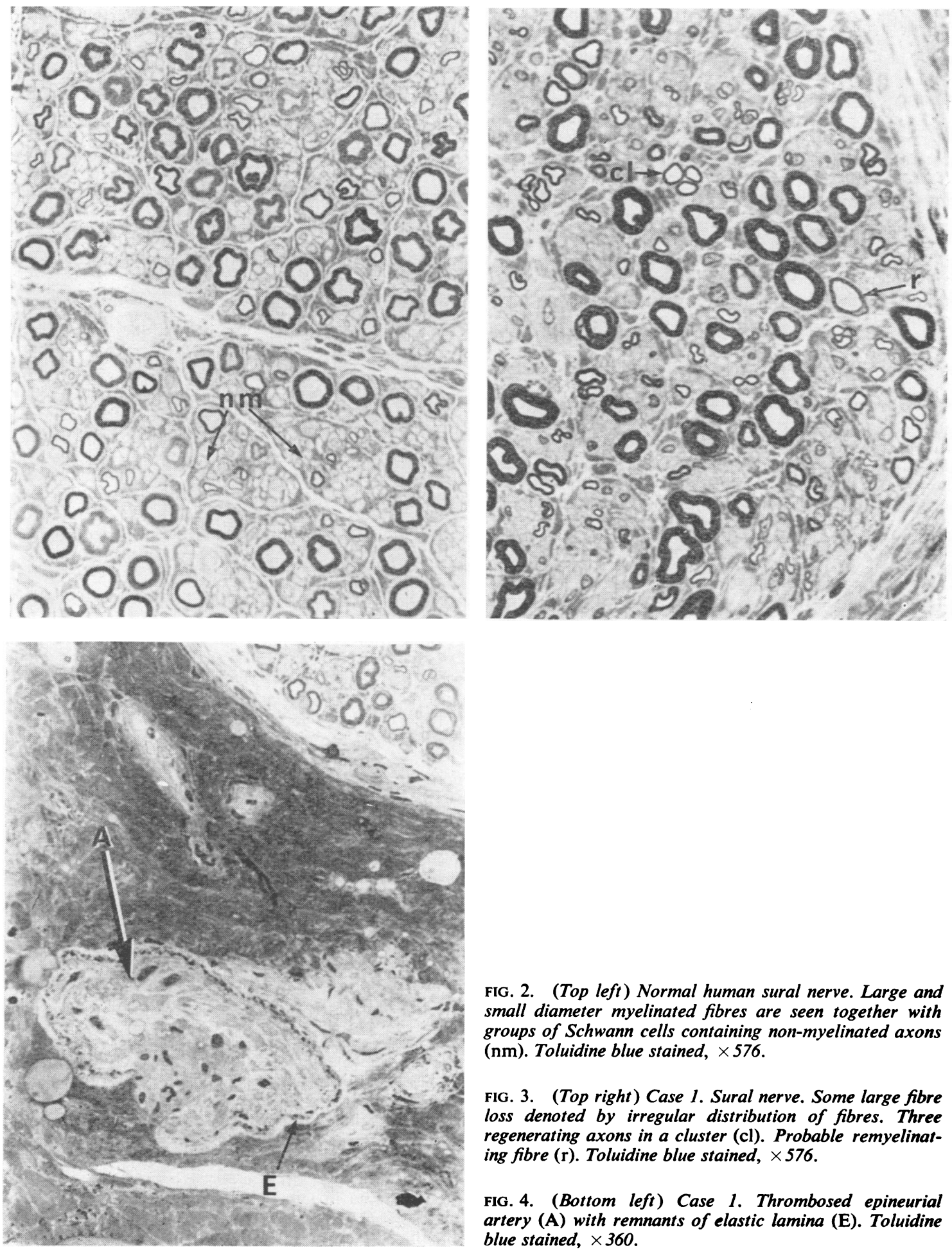

FIG. 2. (Top left) Normal human sural nerve. Large and small diameter myelinated fibres are seen together with groups of Schwann cells containing non-myelinated axons $(\mathrm{nm})$. Toluidine blue stained, $\times 576$.

FIG. 3. (Top right) Case 1. Sural nerve. Some large fibre loss denoted by irregular distribution of fibres. Three regenerating axons in a cluster $(\mathrm{cl})$. Probable remyelinating fibre (r). Toluidine blue stained, $\times 576$.

FIG. 4. (Bottom left) Case 1. Thrombosed epineurial artery (A) with remnants of elastic lamina (E). Toluidine blue stained, $\times 360$. 
comparing the fibre density in cross-sections of the pathological specimens with the normal nerve. In addition, histograms of the myelinated fibre diameters can be compiled to determine whether the large or small fibres are damaged.

Axonal degeneration is detected by the disappearance of myelinated fibres and regeneration is revealed by the presence of small axon sprouts often arranged in clusters (Ochoa and Mair, 1969b). Normal axons with disproportionately thin myelin sheaths have been taken as evidence for segmental demyelination with remyelination (Dyck and Gomez, 1968).

The same criteria for myelinated fibre damage are applied to electron microscopic observations. Also, by this technique, the presence or absence of non-myelinated axons can be confirmed.

\section{RHEUMATOID NEUROPATHY}

GROUP 1 Case 1 Transverse sections of the sural nerve from this patient revealed some reduction in the density of large myelinated fibres (Fig. 3). Among the small myelinated fibres, some were in clusters of two or three fibres which suggests that they were regenerating axon sprouts. Despite this evidence of axonal degeneration the histogram of fibre diameters still maintained its bimodal form (Fig. 1). A few fibres did have disproportionately thin myelin sheaths compatible with remyelination after segmental demyelination. Many groups of non-myelinated fibres were seen and did not appear to be grossly reduced in number.

The endoneurial blood vessels were normal but the large epineurial artery in this nerve was occluded by organizing thrombus (Fig. 4). No perivascular inflammatory cells were seen.

Case 2 The densities of myelinated fibres, both large and small, were normal in the sural nerve biopsy from this patient. In addition there were many non-myelinated fibres present (Fig. 5). As would be expected, the histogram of fibre diameters showed a normal bimodal distribution (Fig. 1). The only abnormality seen in the nerve was a few large fibres with disproportionately thin myelin sheaths suggesting remyelination after segmental demyelination (Fig. 5).

No abnormality was found in the perineurium or epineurium. All the vessels were normal.

Case 3 Light microscopy revealed an oedematous nerve (Fig. 6) with a gross loss of myelinated fibres, especially from the larger diameter group (Fig. 1). Many clusters of small fibres were seen suggesting that some axons were regenerating. Most of the myelinated fibres preserved in this nerve were of small diameter but it was not possible to separate the true small diameter fibres from the regenerating sprouts of larger diameter fibres. Nonmyelinated fibres were detected in the nerve but seemed to be reduced in number.

There were four or five endoneurial blood vessels in any one cross-section of a nerve fasciculus and they were all patent. However, some concentric hypertrophy of these vessels was noticed with several layers of smooth muscle cells around them. In the epineurium there were several small vessels instead of the normal single large vessel. No evidence of vasculitis was seen but the small arteries may possibly represent revascularization follow- 을 ing occlusion of a larger vessel.

GROUP 2 The sural nerve biopsies from both patients in this group were thin, grey, and tough to cut. Microscopic examination revealed extensive loss of fibres from both nerves.

LIGHT MICROSCOPY Case 4 In the whole cross-section of sural nerve from case 4 there were only 10 large myelinated fibres preserved out of many hundreds; they were all within a small area in one nerve fascicle. Figure $7 \overrightarrow{0}$ shows an area moderately well populated by small myelinated fibres; some regions, however, were completely devoid of any myelinated fibres. Clusters of $\frac{\bar{\sigma}}{\bar{N}}$ regenerating axons were seen, so the problem again arises of the distinction between the regenerating sprouts and the true small fibres (Fig. 1).

There was disproportion of axon diameter and myelin sheath thickness in several fibres, suggesting that they. were remyelinating after segmental demyelination $\overrightarrow{\vec{H}}$ (Fig. 7). Throughout the nerve there were many non- $\omega$ myelinated fibres and their numbers did not seem to be at all reduced even in the areas where no myelinated fibres remained.

All the nerve fasciculi contained six or eight blood $c$ vessels but their walls were thickened by layers of spindleo or shaped cells. The portion of epineurial artery seen in this biopsy was normal.

Case 5 The loss of myelinated fibres from the whore cross-section of this nerve was so great that it was not possible to compose a histogram. Figure 8 shows the loss of large and small fibres. Some of the remaining small myelinated nerves may be regenerating sproutes There also appears to be a reduction of non-myelinated fibres with shrinkage of the Schwann cells and sliga increase in collagen.

Although some of the endoneurial blood vessels were normal, others were occluded by thrombus (Fig. 9). Two vessels in eight were thrombosed in the endoneurium but, in addition, the large epineurial vessel was occluded. No inflammatory cells were observed in or around the vessel walls.

ELECTRON MICROSCOPY Case 4 Large numbers of nonmyelinated fibres were seen in this nerve and, in addition, electron microscopy confirmed that segmental demyelination had occurred. A small $(2.5 \mu)$ myelinated fibre is shown in Fig. 10 where the axon-myelin ratio appears to be normal. The much larger axon in Fig. 11 is $6 \mu$ in diameter. This fibre has undergone segmental demyelination $\dot{0}$ and is devoid of a myelin sheath. A stage in remyelination is seen in Fig. 12 where the $3.5 \mu$ axon has a thin myelin sheath and probably some debris from a previous sheath remains in the Schwann cytoplasm.

Case 5 Light microscopy has revealed the extensive loss 은 of myelinated fibres from this nerve and the reduction $D$ in the non-myelinated axons. Some non-myelinated fibres were seen with the electron microscope (Fig. 13) but they $\bar{N}$ were reduced in number. Many Schwann cells had no 5 axons associated with them and some had encircled $N$ bundles of collagen fibres. 

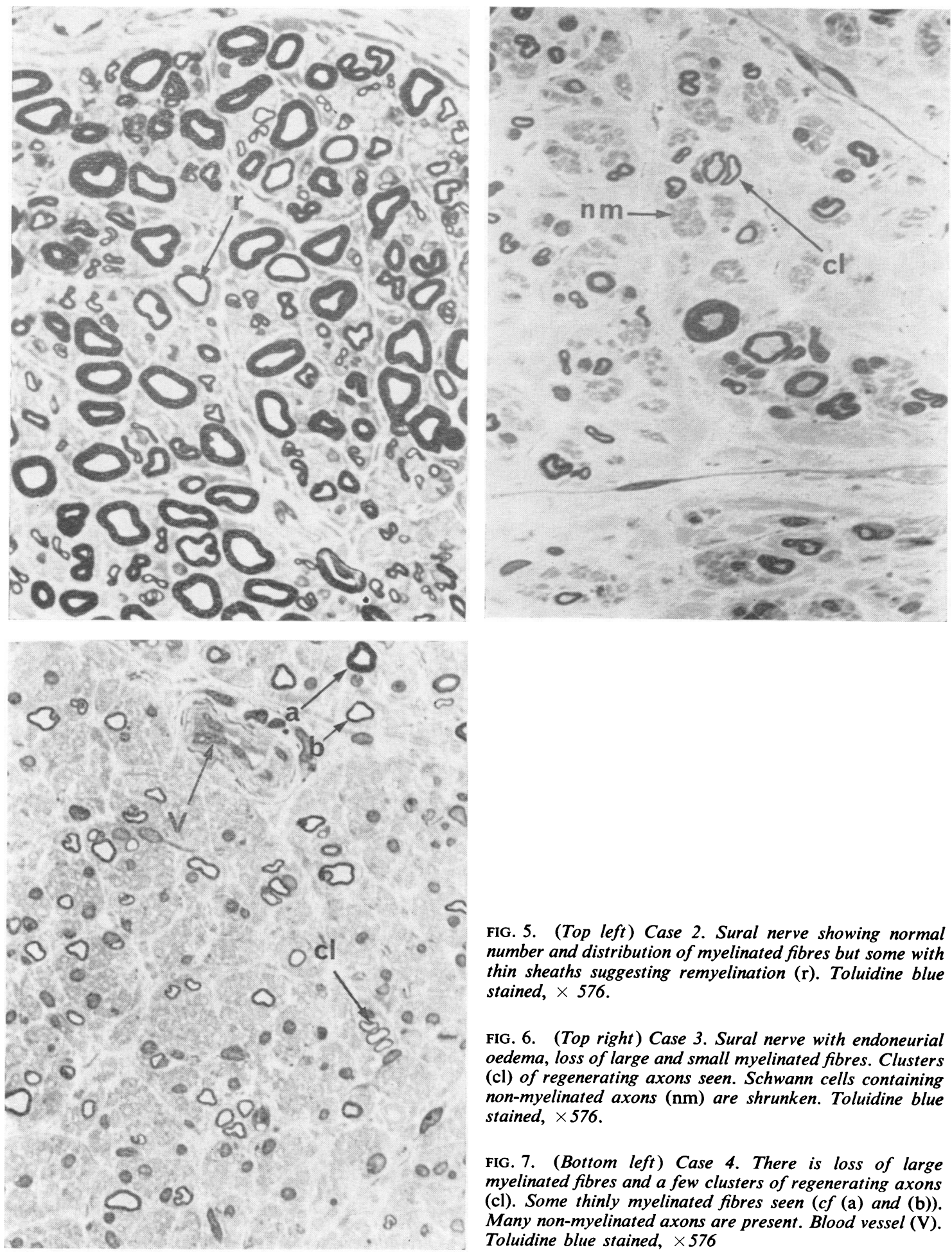

FIG. 5. (Top left) Case 2. Sural nerve showing normal number and distribution of myelinated fibres but some with thin sheaths suggesting remyelination (r). Toluidine blue stained, $\times 576$.

FIG. 6. (Top right) Case 3. Sural nerve with endoneurial oedema, loss of large and small myelinated fibres. Clusters (cl) of regenerating axons seen. Schwann cells containing non-myelinated axons $(\mathrm{nm})$ are shrunken. Toluidine blue stained, $\times 576$.

FIG. 7. (Bottom left) Case 4. There is loss of large myelinated fibres and a few clusters of regenerating axons (cl). Some thinly myelinated fibres seen (cf (a) and (b)). Many non-myelinated axons are present. Blood vessel (V). Toluidine blue stained, $\times 576$ 
FIG. 8. Case 5. Sural nerve with very few myelinated fibres. Shrinkage of the Schwann cells containing nonmyelinated axons (nm) has occurred. Toluidine blue stained, $\times 576$.

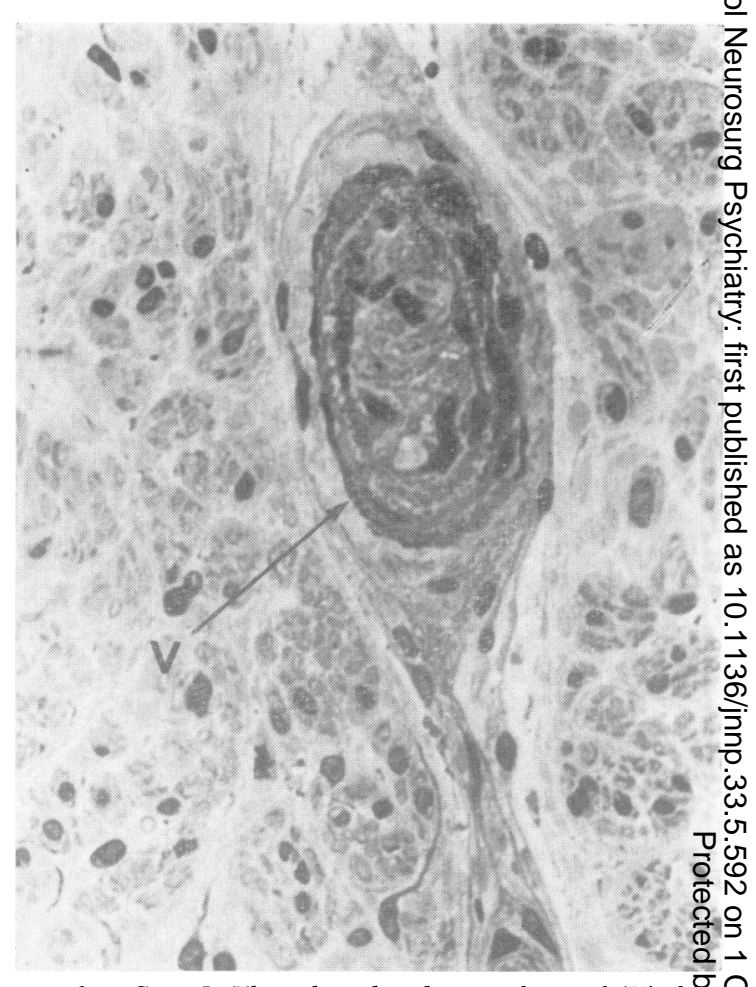

FIG. 9. Case 5. Thrombosed endoneurial vessel (V) from sural nerve. Toluidine blue stained, $\times 576$.

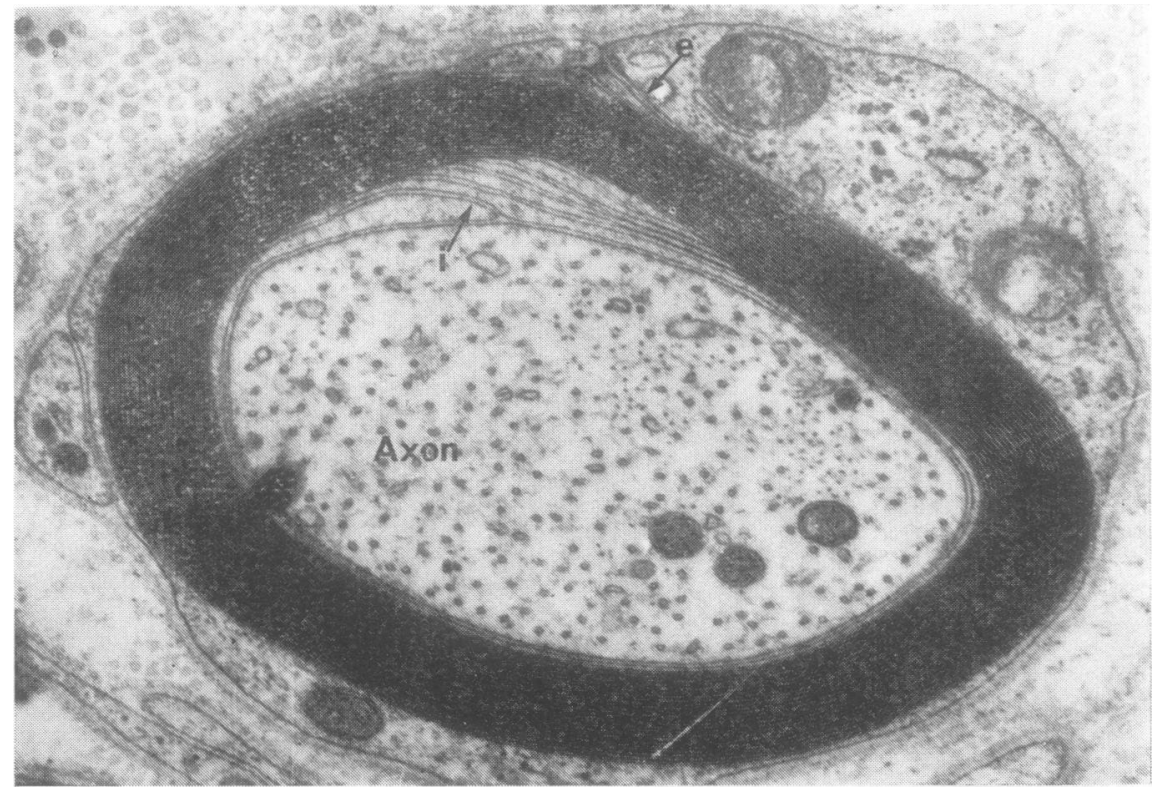

FIG. 10. Case 4. Electron micrograph $2 \cdot 5 \mu$ axon with myelin sheath of normal thickness. External mesaxon (e). Internal mesaxon (i). Stained with lead, $\times 27,000$. 


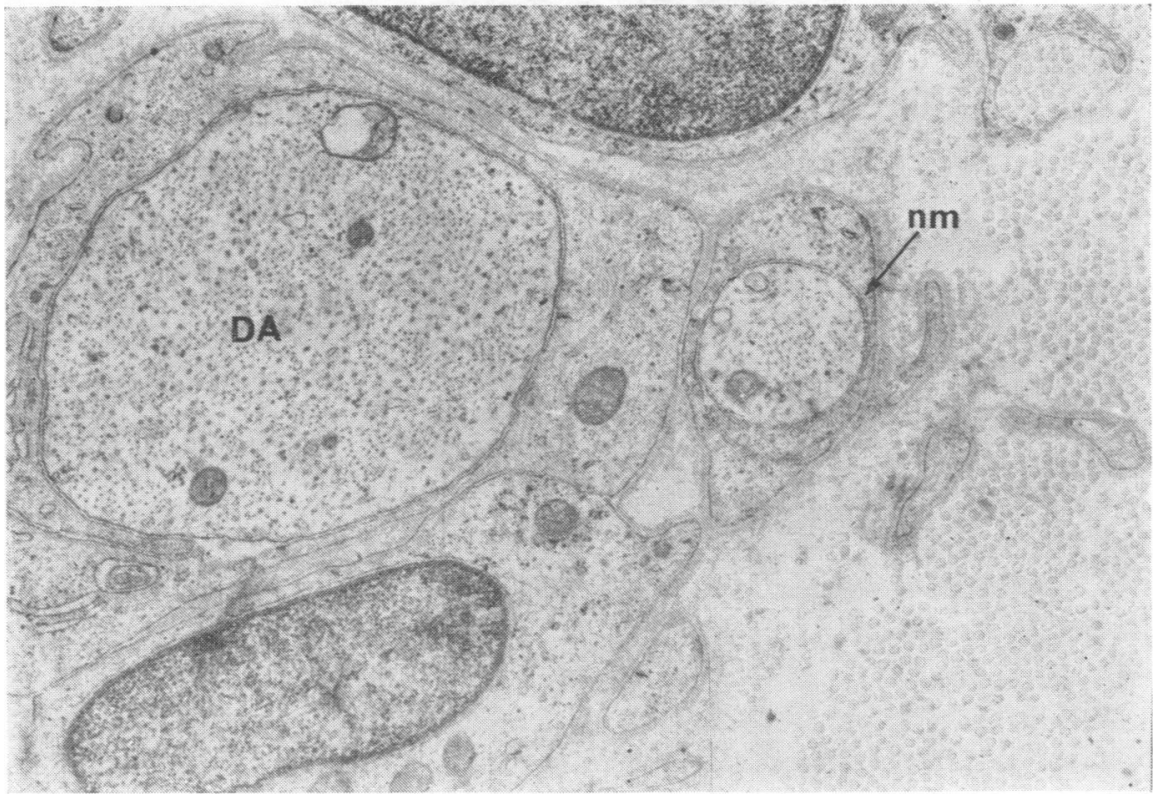

FIG. 11. Case 4. Electron micrograph showing demyelinated $6 \mu$ axon (DA). A small axon that is probably truly non-myelinated $(\mathrm{nm})$ is also seen. Stained with lead, $\times 12,400$.

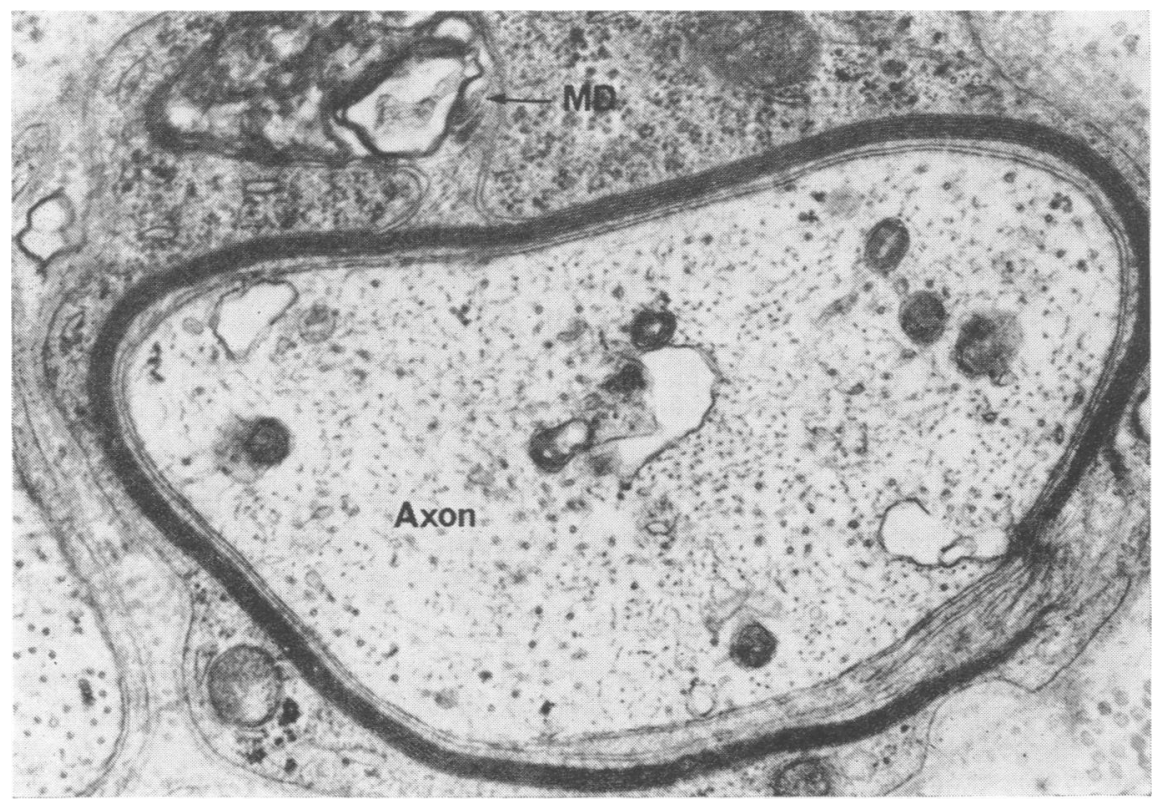

FIG. 12. Case 4. Electron micrograph of a remyelinating fibre. The $3.5 \mu$ axon is encompassed by a thin myelin sheath. Myelin debris (MD). Stained with lead, $\times 24,826$. 


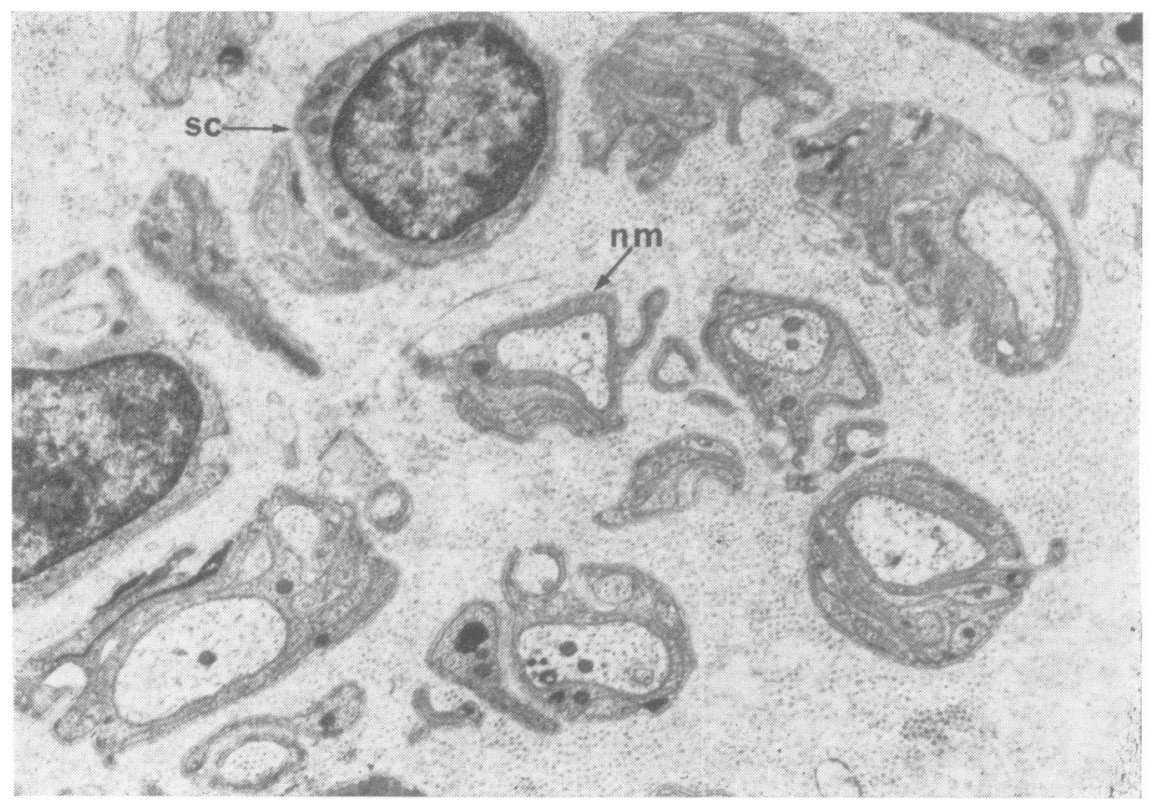

FIG. 13. Case 5. Electron micrograph of non-myelinated fibres $(\mathrm{nm})$. Schwann cells and their processes are seen that are not associated with any axons $(\mathrm{sc})$. Stained with lead, $\times 5,895$.

The blood vessels studied ultrastructurally had patent lumina. Their walls were composed of normal endothelium (Fig. 14) but they were surrounded by loosely packed layers of smooth muscle cells. In addition there was duplication of the basement membranes (Fig. 15). These vessels are probably venules rather than capillaries.

ELECTROPHYSIOLOGY Case 1 (Mrs. I.B.). This patient's right-lateral popliteal nerve showed profound denervation when examined in March 1968, six months before her sural nerve biopsy. There was wasting at the site of the extensor digitorum brevis muscle; no muscular movement was seen here on voluntary dorsiflexion of the foot and no motor units were excitable on direct stimulation over the site of the muscle or on stimulation over the course of the lateral popliteal nerve at the ankle or neck of fibula.

The nerves of both forearms were studied in 1964, 1967, and 1968. On several occasions increased latency was found on median nerve stimulation at the wrist together with slowing of motor nerve conduction in the forearm.

1964, left median nerve: latency at wrist was $12.8 \mathrm{msec}$ with forearm conduction velocity reduced to $24 \mathrm{~m} / \mathrm{sec}$. Increased muscular activity was found on insertion of a concentric needle electrode into abductor pollicis brevis muscle.

1967, right median nerve: nerve-muscle latency at the wrist was increased $(6.5 \mathrm{msec})$ with slow motor nerve conduction in the forearm $(22 \cdot 2 \mathrm{~m} / \mathrm{sec})$.

1968 , right median nerve was again investigated. There was no increased latency at the wrist; the latency to abductor pollicis brevis muscle being $4 \mathrm{msec}$. Motor conduction velocity in the forearm was $55 \mathrm{~m} / \mathrm{sec}$. The patient had, by this time, undergone bilateral carpal tunnel decompression.

There was a slightly reduced amplitude in the sensofy action potential of the right ulnar nerve at this time. The latency to peak (finger-wrist) was normal $(2.3 \mathrm{msec})$.

There is thus evidence of widespread abnormalities peripheral nerves; part of this may have been producege by local compression-for example, of the median nerpec at wrist. But it appears that some nerve changes unrelated 0 to compression had also occurred, as the reduction in velocity in the forearm was greater than would be expected proximal to a compressive lesion.

Case 2 (E.T.) This patient was examined several times between 1967 to 1969 . All findings have been normal. In $\frac{\alpha}{\varnothing}$ the left leg, a mixed nerve potential of $3 \mu \mathrm{V}$ was recorded $\varrho$ from the lateral popliteal nerve; maximum motor fibre $\overrightarrow{\hat{O}}$ conduction velocity of this nerve on the right was found 3 to be $51.5 \mathrm{~m} / \mathrm{sec}$ with a latency of $4.5 \mathrm{msec}$ at the ankle.

The motor conduction velocity of the right mediano nerve in the forearm was $52.5 \mathrm{~m} / \mathrm{sec}$ with a latency of $2 \mathrm{msec}$ at the wrist; the sensory action potential of this nerve had a normal latency also (finger-wrist), and an? amplitude of $17 \mu \mathrm{V}$.

A sensory action potential of $12 \mu \mathrm{V}$ was found in the. right ulnar nerve with a latency to peak of $1.9 \mathrm{msec} \delta$ (finger-wrist).

Case 3 (E.W.) This patient was examined in 1964, 윽 1967, and 1969.

On the first occasion, only the right arm was studied. Normal motor conduction velocities and distal latencies $\bar{N}$ were recorded from the median and ulnar nerves but. sensory action potentials were not elicited from either $N$ nerve. 


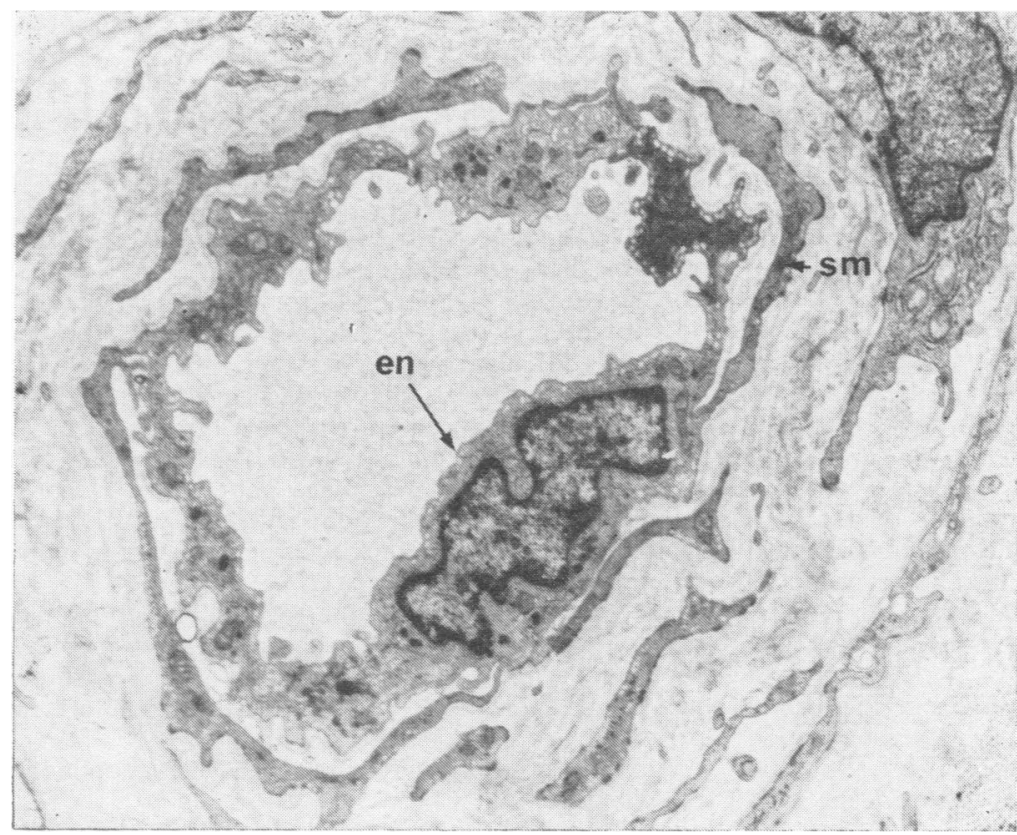

FIG. 14. Case 5. Electron micrograph of endoneurial venule. Epithelium (en) and smooth muscle cells (sm). Stained with lead, $\times 4,800$.

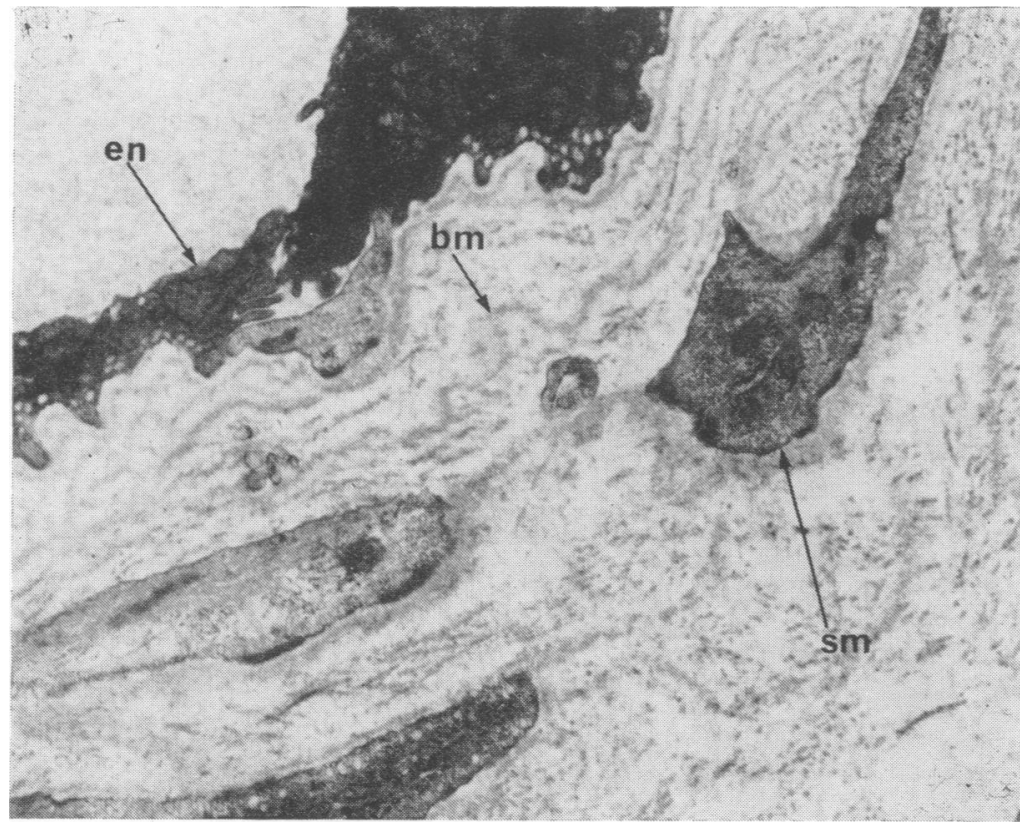

FIG. 15. Higher magnification electron micrograph of vessel wall. Endothelium (en), smooth muscle cells (sm). Several layers of basement membrane (bm) are seen. Stained with lead, $\times 12,320$.

In November 1967, normal motor conduction was found in the left lateral popliteal nerve to the extensor digitorum brevis muscle (conduction velocity $42.4 \mathrm{~m} / \mathrm{sec}$ with $6.2 \mathrm{msec}$ latency from the ankle). No afferent nerve action potential could be found. At this time the left abductor pollicis brevis muscle was grossly wasted and no musculature innervated by the median nerve could be found in the left hand. Thenar muscles innervated by the ulnar nerve showed ill-sustained spontaneous fibrillation, although motor conduction in the left ulnar nerve in the 
forearm was normal (conduction velocity $50 \mathrm{~m} / \mathrm{sec}$; latency of $5.3 \mathrm{msec}$ at the wrist). No sensory nerve action potential was obtained from this nerve.

No afferent nerve action potential was found in the right popliteal nerve in 1969.

This patient thus shows evidence of denervation; several sensory nerve action potentials are absent; motor conduction velocity is normal when found. There is no evidence of any gross slowing consistent with segmental demyelination.

GROUP 2 Case 4 (J.T.) Evidence of severe denervation in both the lateral and the medial popliteal nerves of the right leg was found when this patient was examined in October 1967, some months before his sural nerve biopsy.

The extensor digitorum brevis muscle could not be seen or felt; there were no fibres under voluntary control and stimulation of the lateral popliteal nerve produced no muscle action potentials. Similar results were found when the adductor hallucis longus muscle and medial popliteal nerves were studied.

No afferent potential was elicited from the lateral popliteal nerve at the neck of the fibula. A sensory action potential of $5.5 \mu \mathrm{V}$ (slightly reduced) with a normal latency ( $3 \mathrm{msec})$ was, however, obtained from the right ulnar nerve (finger-wrist).

Case 5 (B.M.) This patient was investigated on several occasions from March 1967 to 1969.

March 1967: no fibrillation was found in either the left or the right extensor digitorum brevis muscles. There were no detectable motor units under voluntary control on the left and, on the right only one motor unit was seen firing in isolation on maximal voluntary effort. The conduction velocity in the motor nerve to this unit was at the lower limit of normal $(36.5 \mathrm{~m} / \mathrm{sec})$ with a normal latency of $4 \mathrm{msec}$ at the ankle. Corresponding values on the left were also normal $(40.5 \mathrm{~m} / \mathrm{sec}, 4.6 \mathrm{msec})$ a few weeks previously.
No afferent nerve action potential was obtained from $z$ either left or right lateral popliteal nerves.

At this time, therefore, there was evidence of severe denervation with preservation of normal motor conduction velocities in the popliteal nerves.

June 1967: the left lateral popliteal nerve was completely denervated: stimulation of the nerve at the neck

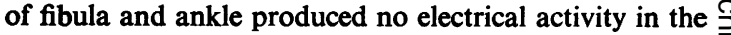
extensor digitorum brevis muscle.

A week later a normal sensory action potential of $15 \mu \mathrm{V}$ with a latency to peak of $2.8 \mathrm{msec}$ was recorded from the left ulnar nerve. However, within two weeks $\stackrel{\vec{D}}{+}$ dysaesthesiae were also experienced in the territories of 0 the right median and ulnar nerves. All motor studies of $\bar{\partial}$ these nerves in the forearm were normal, but there was $\overline{\bar{\omega}}$ a reduction in the interference pattern on maximum $\overrightarrow{\mathbb{D}}$ voluntary activity of the right abductor pollicis brevis $\varrho$ muscle. Both median and ulnar nerve sensory action potentials were absent.

Almost two years later, after over a year's treatment with azathioprine, findings in the right lateral popliteal $\vec{\omega}$ nerve in the territory of the extensor digitorum brevis muscle were unchanged, still indicative of severe denervation.

Evidence of severe and widespread denervation is thus presented.

A summary of the histological and EMG findings in alP five cases is presented in the Table.

\section{DISCUSSION}

Clinical symptoms of peripheral neuropathy wers present in all five patients of this series. The threg cases in group 1 , with a mild sensory neuropathy were less affected than those with the severe sensore motor neuropathy in group 2 .

Histological and electrophysiological findings in the five patients correlated well. In group 1 , case 1

TABLE

SUMMARY OF HISTOLOGICAL AND EMG FINDINGS

\begin{tabular}{|c|c|c|c|c|c|}
\hline & \multicolumn{3}{|c|}{$\begin{array}{c}\text { Group } 1 \\
\text { (Mild sensory neuropathy) }\end{array}$} & \multicolumn{2}{|c|}{$\begin{array}{c}\text { Group } 2 \\
\text { (Severe sensori-motor neuropathy) }\end{array}$} \\
\hline & Case I (I.B.) & Case 2 (E.T.) & Case $3(E . W)$. & Case 4 (J.T.) & Case 5 (E.B.) \\
\hline Loss of myelinated fibres & $\begin{array}{l}\text { Loss of some large } \\
\text { fibres }\end{array}$ & No detectable loss & $\begin{array}{l}\text { Loss of some small } \\
\text { but mainly of large } \\
\text { fibres }\end{array}$ & $\begin{array}{l}\text { Loss of most large } \\
\text { fibres but many } \\
\text { small fibres } \\
\text { preserved }\end{array}$ & $\begin{array}{l}\text { Almost complete } \\
\text { loss of all large } \\
\text { and small myelin- } \\
\text { ated fibres }\end{array}$ \\
\hline Histogram of myelinated fibres & Normal & Normal & $\begin{array}{l}\text { Some loss of large } \\
\text { fibres }\end{array}$ & Loss of large fibres & $\begin{array}{l}\text { Severe loss large } \\
\text { and small fibres }\end{array}$ \\
\hline Non-myelinated axons & Appear normal & Appear normal & Some loss & Appear normal & Moderate loss \\
\hline Type of myelinated fibre damage & $\begin{array}{l}\text { Mainly axonal } \\
\text { degeneration; } \\
\text { some segmental } \\
\text { demyelination }\end{array}$ & $\begin{array}{l}\text { No damage } \\
\text { detected }\end{array}$ & Axonal degeneration & $\begin{array}{l}\text { Mainly axonal } \\
\text { degeneration; } \\
\text { some segmental } \\
\text { demyelination }\end{array}$ & $\begin{array}{l}\text { Axonal } \\
\text { degeneration }\end{array}$ \\
\hline Vessels within sural nerve biopsy & $\begin{array}{l}\text { Occluded, } \\
\text { thrombosed } \\
\text { epineurial artery }\end{array}$ & Normal & $\begin{array}{l}\text { Many small } \\
\text { epineurial vessels } \\
\text { No recent occlusion }\end{array}$ & Normal & $\begin{array}{l}\text { Epineurial and } \\
\text { endoneurial vessels } \\
\text { thrombosed }\end{array}$ \\
\hline EMG & $\begin{array}{l}\text { Widespread } \\
\text { denervation }\end{array}$ & Normal & $\begin{array}{l}\text { Denervation in } \\
\text { several nerves }\end{array}$ & $\begin{array}{l}\text { Severe } \\
\text { denervation }\end{array}$ & $\begin{array}{l}\text { Widespread severe } \\
\text { denervation }\end{array}$ \\
\hline Clinical evidence of vasculitis & None & None & None & $\begin{array}{l}\text { Nailfold lesions, } \\
\text { leg ulcer }\end{array}$ & $\begin{array}{l}\text { Nailfold lesions, } \\
\text { gastric ulcer }\end{array}$ \\
\hline
\end{tabular}


showed histological and electrophysiological evidence of denervation, but there was not enough differential loss of fibres in the sural nerve biopsy to alter the shape of the fibre diameter histogram. Case 2, on the other hand, showed neither histological nor EMG evidence of denervation despite her clinical symptoms. She may, however, have suffered some degree of segmental demyelination. The nerves in case 3 had the most damage in group 1 with denervation on EMG and enough loss of large diameter fibres, histologically, to alter the shape of the histogram.

The nerves in group 2 patients were more extensively denervated. Case 4 had lost most of the large fibres in the sural nerve biopsy and showed widespread denervation on EMG. There was some histological evidence of segmental demyelination of both large and snall diameter fibres. The non-myelinated axons were the best preserved group of fibres. In case 5 , axonal degeneration was found histologically in all groups of fibres, both myelinated and nonmyelinated. EMG also revealed widespread denervation.

Hart and Golding (1960) studied the peripheral nerves in five cases of rheumatoid neuropathy at necropsy and found 'demyelination' in only one patient; this was probably axonal degeneration. Areas of segmental demyelination, on the other hand, were found in the nerves of one case of distal sensory neuropathy from the series reported by Pallis and Scott (1965), but no observations were made upon the more severe cases.

Despite the wide range of severity and rate of progression of the clinical signs and symptoms in the two groups of rheumatoid neuropathy, the aetiology of the nerve damage may be very similar. Definite evidence of vascular occlusion of the vasa nervorum was seen in case 1 , case 5 , and possibly in case 3 . In each instance there were no inflammatory cells associated with the thrombosed vessels. Other workers have reported vasculitis and occlusion of vasa nervorum in rheumatoid arthritis as a feature of generalized vasculitis and suggested that this may be the major cause of the nerve damage (Hart and Golding, 1960; Schmid, Cooper, Ziff, and McEwan, 1961 ; Scott, Hourihane, Doyle, Steiner, Laws, Dixon, and Bywaters, 1961; Pallis and Scott, 1965). The histological findings in the vessels in our cases were similar to the bland intimal thickening and thrombosis described by Bywaters (1957) in his study of peripheral vascular obstruction in rheumatoid arthritis.

Many of the endoneurial blood vessels in the sural nerves were not occluded but were surrounded by several layers of smooth muscle cells and by duplicated basement membrane. These appearances may be normal in leg nerve venules of older people. Eames and Lange (1967), however, observed similar features in vasa nervorum from patients with ischaemic limbs.

The pattern of nerve fibre damage in rheumatoid neuropathy follows closely that observed in ischaemic neuropathy (Garven, Gairns, and Smith, 1962; Eames and Lange, 1967) and after the local application of phenol (Schaumberg, Byck, and Weller, 1970). Large myelinated fibres seem to be the most susceptible, first undergoing segmental demyelination but with further insult many axons in this group degenerate. Even at this point, however, the smaller myelinated fibres may still be preserved or only undergoing segmental demyelination, as in case 4 of the present series. Axons of small myelinated fibres degenerate as damage increases, as in case 5 , and then perhaps last of all, the non-myelinated fibres die.

The difference in nerve damage between group 1 and group 2 of our series is mainly one of severity. Vasculitis and occlusion are more widespread in the severe cases of rheumatoid arthritis so that the frequency of vasa nervorum involvement is probably increased. If the vascular supply is interrupted only in sporadic, widely separated portions along the length of the nerve, the collateral circulation may prevent complete infarction and axonal degeneration. Adams (1943) showed, in the rabbit sciatic, that the integrity of the intraneural longitudinal vascular anastomoses is important in preserving the nerve. If these channels are extensively blocked by thrombus, severe damage and axonal degeneration may take place.

In rheumatoid neuropathy the number of intraneural vessels occluded probably varies from patient to patient causing different degrees of ischaemia. Thus, segmental demyelination occurs in the least affected nerves (Pallis and Scott, 1965) and axonal degeneration accompanies the more widespread vascular occlusion. Some support for this suggestion is found in another part of the present study where Chamberlain and Bruckner (1970) investigated 32 patients electrophysiologically. Some of the group 1 subjects with a mild sensory neuropathy showed marked slowing of conduction in motor nerves with little clinical abnormality. This suggests segmental demyelination. The more severely affected patients in group 2, however, had marked denervation with little slowing of conduction, suggesting primary axonal degeneration. Unfortunately no nerve biopsies were available from the patients in group 1 with very slow conduction velocities.

Sporadic axonal degeneration along a nerve trunk means that the long fibres supplying the extremities are more likely to be damaged. This cumulative 
effect upon the long fibres observed by Garven et al. (1962) in the nerves of ischaemic limbs may account for the predominantly distal distribution of rheumatoid neuropathy especially in group 2 . Another important factor in determining the involvement of the extremities is the extensive digital arteritis observed by Scott et al. (1961) in both mild and severe neuropathies.

Detailed investigation of our five cases of rheumatoid neuropathy has revealed a close correlation between the clinical severity of the neuropathy and the amount of nerve fibre damage. Furthermore, the close agreement between the histological picture in the sural nerve biopsies and the EMG suggests that the peripheral nerves damage may be widespread despite the predominantly distal distribution of the clinical signs.

We wish to thank Dr. P. M. Fullerton for her very valuable help and advice in this study; Dr. A. C. Boyle for permission to study his patients, and Mr. J. Andrew and his staff for performing the biopsies. Mr. G. Stevens and Mrs. T. M. Philips contributed their technical assistance. This work was supported by grants from the Arthritis and Rheumatism Council and the Medical Research Council.

\section{REFERENCES}

Adams, W. E. (1943). The blood supply of nerves: II. The effects of exclusion of its regional sources of supply on the sciatic nerve of the rabbit. J. Anat. (Lond.), 77, 243-250.

Bywaters, E. G. L. (1957). Peripheral vascular obstruction in rheumatoid arthritis and its relationship to other vascular lesions. Ann. rheum. Dis., 16, 84-103.

Chamberlain, M. A., and Bruckner, F. E. (1970). Clinical and electrophysiological features of rheumatoid neuropathy. Ann. rheum. Dis. (in press).

Cruickshank, B. (1954). The arteritis of rheumatoid arthritis. Ann. rheum. Dis., 13, 136-146.

Dawson, G. D. (1956). The relative excitability and conduction velocity of sensory and motor nerve fibres in man. J. Physiol. (Lond.), 131, 436-451.
Dyck, P. J., Gutrecht, J. A., Bastron, J. A., Karnes, W. E., and Dale, A. J. D. (1968). Histologic and teased-fiber measurements of sural nerve in disorders of lower motor and primary sensory neurons. Mayo Clin. Proc., 43, 81-123.

Dyck, P. J., and Gomez, M. R. (1968). Segmental demyelinization in Dejerine-Sottas disease. Mayo Clin. Proc., 43, 280-296.

Eames, R. A., and Lange, L. S. (1967). Clinical and pathological study of ischaemic neuropathy. J. Neurol. Neurosurg. Psychiat., 30, 215-226.

Gamble, H. J., and Eames, R. A. (1964). An electron microscope study of the connective tissues of human peripheral nerve. J. Neurol. Neurosurg. Psychiat., 98, 655-663.

Garven, H. S. D., Gairns, F. W., and Smith, G. (1962). The nerve fibre populations of the nerves of the leg in chronic occlusive arterial disease in Man. Scot. med. J., 7, 250-265.

Gilliatt, R. W., Goodman, H. V., and Willison, R. G. (1961). The recording of lateral popliteal nerve action potentials in Man. J. Neurol. Neurosurg. Psychiat., 24, 305-318.

Hart, F. D., and Golding, J. R. (1960). Rheumatoid neuropathy. Brit. med.J., 1, 1594-1600.

Ochoa, J., and Mair, W. G. P. (1969a). The normal sural nerve in man. $I$. Ultrastructure and numbers of fibres and cells. Acta neuropath. (Berl.), 13, 197-216.

Ochoa, J., and Mair, W. G. P. (1969b). The normal sural nerve in man. II. Changes in the axons and Schwann cells due to ageing. Acta neuropath. (Berl.), 13, 217-239.

Palade, G. E. (1952). A study of fixation for electron microscopy. J. exp. Med., 95, 285-298.

Pallis, C. A., and Scott, J. T. (1965). Peripheral neuropathy in rheumatoid arthritis. Brit. med. J., 1, 1141-1147.

Schaumberg, H., Byck, R., and Weller, R. O. (1970). Electro-D physiological histological and ultrastructural changes in cat saphenous nerve following phenol perfusion. J. Neuropath. exp. Neurol. (in press).

Schmid, F. R., Cooper, N. S., Ziff, M., and McEwen, C. (1961). Arteritis in rheumatoid arthritis. Amer. J. Med. 30, 56-83.

Scott, J. T., Hourihane, D. O., Doyle, F. H., Steiner, R. E. Laws, J. W., Dixon, A. St., and Bywaters, E. G. L. (1961) Digital arteritis in rheumatoid disease. Ann. rheum. Dis.; 20, 224-234.

Thomas, P. K., Sears, T. A., and Gilliatt, R. W. (1959). The range of conduction velocity in normal motor nerve fibres to the small muscles of the hand and foot. J. Neurol. Neurosurg. Psychiat., 22, 175-181.

Weller, R. O. (1967). An electron microscopic study of hypertrophic neuropathy of Dejerine and Sottas. $J$. Neurol. Neurosurg. Psychiat., 30, 111-125. 